УДК 141.5

DOI 10.18413/2712-746X-2020-44-2-371-375

\title{
Экзистенциальные смыслы свободы в творческом наследии А.С. Хомякова
}

\author{
Липич Т.И., Логинова Н.В. \\ Белгородский государственный национальный исследовательский университет, \\ Россия, 308015, г. Белгород, ул. Победы, 85 \\ E-mail: Lipich@bsu.edu.ru, loginova@bsu.edu.ru
}

\begin{abstract}
Аннотация. Свобода является ключевым понятием славянофильского миропонимания. А.С. Хомяков один из первых рассматривал проблему свободы сквозь призму христианского понимания человека. Трактовка свободы у славянофилов отлична от трактовки свободы воли и свободы выбора в западной философской мысли. А.С. Хомяков ставит во главу угла свободы личности любовь божественную, считая, что если человек грешен, то любовь может привести к эгоизму, который разрушает цельность личности. Личная свобода, по его мнению, неотделима от соборной личности. В статье рассматриваются категории «соборность», «иранство» и «кушитство», «волящий разум».
\end{abstract}

Ключевые слова: славянофилы, соборность, целостность духа, личность, иранство и кушитство, волящий разум, свобода.

Для цитирования: Липич Т.И., Логинова Н.В. 2020. Экзистенциальные смыслы свободы в творческом наследии A.C. Хомякова. NOMOTHETIKA: Философия. Социология. Право. 45 (2): 371-375. DOI 10.18413/2712-746X-2020-44-2-371-375

\section{Existential meanings of freedom in the creative heritage of A.S. Khomyakov}

\author{
Tamara I. Lipich, Natalia V. Loginova \\ Belgorod State National Research University, \\ 85 Pobeda St., Belgorod, 308015, Russia \\ E-mail: Lipich@bsu.edu.ru, loginova@bsu.edu.ru
}

\begin{abstract}
Turning to anthropological topics is a characteristic feature of philosophical reflections at different stages of the historical development of mankind. Each era, possessing an integral and unique culture, proposed its own solutions to this problem. A man, his inner world reacted in a certain way to external circumstances, formed his own value outlook on the world, and also comprehended the meanings of his own freedom. Thus, human models were formed in various historical eras. In this sense, the 19th century was no exception. But it was precisely at this time that the polarization of thinkers' views on the problem of man, on his nature, essence and purpose, and, consequently, the purpose and meaning of his existence, is most clearly manifested. Russian philosophy at the center of its research posed the question of the integrity of human life as a universal center of the world. Freedom is a key concept of the Slavophile worldview. Khomyakov was one of the first to consider the problem of freedom through the prism of a Christian understanding of man. The interpretation of freedom among the Slavophiles is different from the interpretation of free will and freedom of choice in Western philosophical thought. Khomyakov puts love, divine love at the forefront of the individual's freedom, believing if a person is sinful and love can lead to selfishness that destroys the integrity of the individual. Freedom as voluntariness in decision making based on love of God. Personal freedom, in his opinion, is inseparable from the conciliar person. The article examines the categories of collegiality, "Iranianism" and "kushitstvo", "volitional mind".
\end{abstract}


Keywords: Slavophiles, collegiality, integrity of the spirit, personality, Iranism and Couchines, willing mind, freedom.

For citation: Lipich T.I., Loginova N.V. 2020. Existential meanings of freedom in the creative heritage of A.S. Khomyakov. NOMOTHETIKA: Philosophy. Sociology. Law series. 45 (2): 371-375. (in Russian). DOI 10.18413/2712-746X-2020-44-2-371-375

\section{Введение}

Обращение к антропологической тематике является характерной особенностью философских размышлений на разных этапах исторического развития человечества. Каждая эпоха, обладая цельной и уникальной культурой, предлагала свои решения этой проблемы. Человек, его внутренний мир, определённым образом реагировал на внешние обстоятельства, формировал собственный ценностный взгляд на мир, а также постигал смыслы собственной свободы. Так формировались модели человека в различные исторические эпохи. В этом смысле ХІХ век не стал исключением. Но именно в это время наиболее ярко проявляется поляризация взглядов мыслителей на проблему человека, его природу, сущность и предназначение, а следовательно, на цель и смысл его существования. Русская философия в центр своих исследований поставила вопрос о цельности человеческого бытия как универсального центра мира. Именно эта идея стала одной из важнейших в русской философии на протяжении ее развития.

В первой половине XIX века постепенно формируется философскоантропологическая традиция, которую можно назвать духовной антропологией. И одними из первых, кто обратился к этой проблематике, были П.Я. Чаадаев, славянофилы в лице И.В. Киреевского и С.А. Хомякова. Прежде всего, их внимание было заострено на полемических выводах П.Я. Чаадаева, который считал, что именно человек является исходным принципом для решения важнейших социальных задач в ходе развития человечества, что человек подчинен Божественному нравственному закону. Он обращал свои взоры к религиозной философии, считая, что она сможет познать «тайну назначения человека». Метафизика человека, рассматриваемая сквозь призму «верующего разума», «волящего разума», «цельности духа», наполняла глубокими экзистенциальными смыслами понятие свободы, являющейся одной из главных характеристик человеческого бытия.

\section{Смыслы свободы}

Современный русский религиозный философ, публицист, профессор Питтсбургского университета Полторацкий характеризовал следующим образом русскую философию: «Русская религиозная философия с ее антропоцентризмом, моральной установкой, социальной ориентированностью и историософичностью, равно как и с ее теоретическипрактической целостностью, пронизана необычайной свободой духа. Самое учение о свободе как основе христианства, разрабатывавшееся русской религиозной философией, связывалось с учением о соборности и онтологизме» [1975, с. 80].

Одним из первых, кто рассматривал проблему свободы сквозь призму христианского понимания человека, его сущности, был основатель славянофильства А.С. Хомяков, который не мог остаться равнодушным к размышлениям П.Я. Чаадаева.

Н.А. Бердяев справедливо отмечал, что именно А.С. Хомяков положил начало в русской религиозной философии серьезному анализу понятия христианской свободы. В одной из своих работ он пишет: «Наступила эпоха, когда должна была быть раскрыта христианская свобода более, чем это было раскрыто в прежние эпохи. У старых учителей Церкви мы не находим такого учения о христианской свободе, как у Хомякова. Но потому-то и велика творческая заслуга Хомякова. Русская православная мысль ХIX века раскрывает в христианстве то, что не было достаточно раскрыто. Проблема свободы стоит в 
центре русской религиозной мысли, на этой проблеме она себя противополагает мысли католической <...> Проблема о человеке стоит в центре нового сознания. И нужно было начать раскрывать христианское учение о человеке, о его призвании в мире $<\ldots>$ Если в традиционном учении Церкви нет такого учения о свободе и человеке, то это указывает на его неполноту и недостаточную раскрытость христианской истины. В этом была творческая задача русской религиозной мысли. То была мысль проблематическая, с сильным профетическим элементом. Первое, что утверждала русская религиозная мысль XIX века, это христианскую свободу. И она сделала это в форме, еще не бывшей в истории христианского сознания. Хомяков и Достоевский были у нас главными глашатаями христианской свободы. Все богословствование Хомякова есть гимн христианской свободе. Для него не только церковная иерархия, не только Церковь не есть авторитет, но не есть авторитет и Бог. Категория авторитета применима лишь к низшему плану бытия. Она унижает величие Бога. Бог есть свобода, и в свободе лишь может он раскрываться» [Бердяев, 1936, с. 318].

Соглашаясь с Н.А. Бердяевым, отметим, что А.С. Хомяков один из первых, кто развернул философскую мысль в этом направлении. Он (А.С. Хомяков) расширил задачи изучения свободы личности и сумел раскрыть христианское представление человека поновому - как цельную свободную личность. Это - одно из ключевых понятий его размышлений, оно несло в себе элемент мирского восприятия веры, человека, при этом мыслитель уделял особое внимание идее духовной свободы, которая, на наш взгляд, предопределяла ход развития всей русской религиозно-философской мысли. Некоторые современные мыслители, например, А.Ф. Замалеев, упрекали Хомякова в недостатке православия. Мы считаем, что в данном случае говорить о том, что у родоначальника славянофильства было «мало православия», не совсем точно. Скорее, можно упрекнуть его в том, что он хотел построить Соборную церковь во всем мире. Остановимся более подробно на позиции А.С. Хомякова в этом вопросе.

Для мыслителя одним из определяющих категорий, характеризующих личность, является понятие «волящий разум», выступающий тем духовным началом, субстанцией, которая творит и созидает мир, но вместе с тем не растворяется в нем и не дробится на части. «Волящий разум», основная характеристика свободы человека, никогда не переходит в сферу необходимости. В тоже время он является и первопричиной всех явлений и не зависит от внешних факторов. По мнению А.С. Хомякова, необходимость и свободно «волящий разум» обретают свой концептуальный смысл в двух непримиримых направлениях, двух типах религий, сформировавшихся в истории человечества, - это «иранство» и «кушитство», которые сформировали два типа личности: иранский и кушитский. Он также утверждал, что в каждой личности борются эти два начала: свобода и необходимость

Коренная духовная свобода Творца, из которой формируется понятие добра и нравственное начало творчества, провозглашается в религии «иранства. «Кушитство», по мнению А.С. Хомякова, основываясь на вещественной необходимости при этом не отрицая творца, отрицает само понятие свободы, творческий акт. Он считает, что «вещественная необходимость», олицетворяющая «внешний авторитет», или власть, есть не что иное, как «проявленная свобода», т.е. необходимость, которая не дает возможности развитию свободы творчества. Личность может быть свободна, только определив для себя собственный идеал, высший нравственный закон, осознавая возможность и необходимость ему следования. Только этот высший нравственный, божественный закон - закон любви дает свободу личности.

Ставя во главу угла свободы личности любовь, любовь божественную, он так же предупреждает, что человек грешен и любовь может привести к эгоизму, который разрушает цельность личности. Стоит отметить, что А.С. Хомяков подразумевал естественную, ненасильственную любовь человека к Богу и естественное принятие Божеского закона не как закона, а как свободы. 
Таким образом, только «иранство», выраженное в православии, дает подлинную религиозно-нравственную свободу творящего человеческого духа. Такая свобода может быть обретена только в Церкви, которая выступает первоосновой всего бытия. Человек, обретая веру, обретает свободу в единомыслии с Церковью. Из этого А.С. Хомяков формулирует понятие соборности, которая основывается на всеобщей любви к абсолютным ценностям и друг к другу.

Современный исследователь Т.И. Благова характеризует соборность у Хомякова следующим образом: «Соборность означает церковную общность людей, объединенных верой, православные ценности, гарантирующие духовную целостность личности, истинность познания, примирение в христианской любви свободы каждого и единства всех» [Благова, 1994, с. 180].

Таким образом, А.С. Хомяков понимал свободу как добровольность в принятии решений на основе любви к Богу. Он писал: «Мы свободны, потому что восхотел этого Бог и потому что завоевал нам свободу Христос свободою своего жертвоприношения» [Хомяков, 1994, с. 308].

И еще мы находим ряд высказываний о свободе в его трудах, например, «единство Церкви есть не иное что как согласие личных свобод», или «свобода и единство - таковы две силы, которым достойно вручена тайна свободы человеческой во Христе» [Хомяков, 1994, c. 183].

Следовательно, трактовка свободы у А.С. Хомякова была отлична от трактовки свободы воли или свободы выбора в западной философской мысли, и на этот факт указывает в своих рассуждениях С.C. Хоружий [2002]. Он отмечает, что такое понимание свободы «имеет явные патристические корни», упоминая преп. Максима Исповедника: «Свобода природная» противоположна обычной эмпирической свободе выбора, она определяется отношением к собственной природе, как «бытийная стратегия человека», которая заключается в реализации человеком своего онтологического «телоса», предназначения [Хоружий, 2002, с. 31].

\section{Заключение}

Таким образом, характеризуя понятие личной свободы, А.С. Хомяков имел ввиду возможность человека «возвышаться над собой», постоянно преодолевать свою греховность, свои внутриличностные экзистенциальные конфликты, повышать свой уровень развития и образования. В свою очередь, идея соборности, неотделимая от свободы личности и сама выступающая соборной личностью, провозглашала гармонию частного и общего, выражающуюся во всеобщей Божественной любви.

\section{Список литературы}

1. Бердяев Н.А. 1936. О характере русской религиозной мысли XIX века. Современные записки, 62: 309-343.

2. Бердяев Н.А. 1994. Философия свободного духа. М., Республика, 480 с.

3. Бердяев Н.А. 2001. О назначении человека. Опыт парадоксальной этики. В кн.: Путь в философию. Антология. М., ПЕР СЭ; СПб., Университетская книга, 445 с.

4. Благова Т.И. 1994. Соборность как философская категория у А.С. Хомякова. В кн.: Славянофильство и современность. СПб., Наука: 177-191.

5. Евлампиев И. И. Метафизическое измерение «русской идеи» (П. Чаадаев, В. Одоевский, А. Хомяков). В кн.: Философский век. Альманах. Идея истории в российском просвещении. СПб., 1998: 21-52.

6. Замалеев А.Ф. 1995. Лекции по истории русской философии. СПб., Изд-во СПбГУ, 338.

7. Полторацкий Н.П. 1975. Русская религиозно-философская мысль ХХ века: Сборник статей. Питтсбург, 413 с. 
8. Хомяков А.С. 1994. Сочинения. В 2-х т. Т. 2. М., Московский философский фонд Издательство "Медиум", 497 с.

9. Хоружий С.С. 2000. О старом и новом. СПб., Алетейя, 477 с. Омега: 144 с.

10. Хоружий С.С. 2002. Современные проблемы православного миросозерцания. М.,

11. Чаадаев П.Я. 1989. Сочинения. М., Правда, 655 с.

12. Чаадаев П.Я. 1989. Статьи и письма. М., Современник, 623 с.

\section{References}

1. Berdyayev N.A. 2001. O naznachenii cheloveka. Opyt paradoksal'noy etiki [About the appointment of a person. Experience of paradoxical ethics]. In: Put' v filosofiyu. Antologiya. Moscow, PER SE; Saint-Petersburg, Universitetskaya kniga, 445 p.

2. Berdyayev N.A. 1936. O kharaktere russkoy religioznoy mysli XIX veka [On the nature of Russian religious thought of the 19th century]. Sovremennyye zapiski, 62: 309-343.

3. Berdyayev N.A. 1994. Filosofiya svobodnogo dukha [Philosophy of a free spirit]. Moscow, Respublika, 480 p. (in Russian)

4. Blagova T.I. 1994. Sobornost' kak filosofskaya kategoriya u A.S. Khomyakova [Sobornost as a philosophical category in AS Khomyakova]. In: Slavyanofil'stvo i sovremennost'. Saint-Petersburg, Nauka: $177-191$.

5. Yevlampiyev I.I. Metafizicheskoye izmereniye «russkoy idei» (P. Chaadayev, V. Odoyevskiy, A. Khomyakov) [The metaphysical dimension of the "Russian idea" (P. Chaadaev, V. Odoevsky, A. Khomyakov)]. In: Filosofskiy vek. Al'manakh. Ideya istorii v rossiyskom prosveshchenii. Saint-Petersburg, 1998: 21-52.

6. Zamaleyev A.F. 1995. Lektsii po istorii russkoy filosofii [Lectures on the history of Russian philosophy]. Saint-Petersburg, Izd-vo SPbGU, 338 p.

7. Poltoratskiy N.P. 1975. Russkaya religiozno-filosofskaya mysl' XX veka: Sbornik statey [Russian religious and philosophical thought of the XX century: Collection of articles]. Pittsburg, $413 \mathrm{p}$.

8. Khomyakov A.S. 1994. Sochineniya [Works]. Vol. 2. Moscow, Moskovskiy filosofskiy fond Izdatel'stvo "Medium", $497 \mathrm{p}$.

9. Khoruzhiy S.S. 2002. Sovremennyye problemy pravoslavnogo mirosozertsaniya [Modern problems of the Orthodox worldview]. Moscow, Omega: 144 p.

10. Khoruzhiy S.S. 2000. O starom i novom [About the old and the new]. Saint-Petersburg, Aleteyya, $477 \mathrm{p}$.

11. Chaadayev P.YA. 1989. Sochineniya [Works]. Moscow, Pravda, 655 p.

12. Chaadayev P.YA. 1989. Stat'i i pis'ma [Articles and letters]. Moscow, Sovremennik, 623 p.

\section{ИНФОРМАЦИЯ ОБ АВТОРАХ}

Липич Тамара Ивановна, доктор философских наук, профессор, заведующий кафедрой философии и теологии Белгородского государственного национального исследовательского университета, г. Белгород, Россия

Логинова Наталья Владимировна, аспирант кафедры философии и теологии Белгородского государственного национального исследовательского университета, г. Белгород, Россия

\section{INFORMATION ABOUT THE AUTHOR}

Tamara I. Lipich, Ph.D., Professor, Head of the Department of Philosophy and Theology, Belgorod National Research University, Belgorod, Russia

Natalia V. Loginova, Postgraduate Department of Philosophy and Theology, Belgorod National Research University, Belgorod, Russia 